\title{
La democracia des-mediada. Corrupción y democracia en la modernidad'
}

Sergio D. Morresi

\section{Resumo}

Este trabalho de teoria política toma a problemática da corrupção (entendida não só no sentido de "propina", mas também no sentido mais abrangente de desatenção do mandato político) como eixo para disparar uma rediscussão do debate entre o liberalismo e o republicanismo, aqui encarnados nos federalistas e antifederalistas americanos. A partir de aí, se desenvolvem algumas hipóteses sobre como a diminuição de instancias de mediação pode servir para pelo menos conter a corrupção nos Estados modernos.

Algunos analistas políticos (Gabetta, 2002; Halimi, 2002) han notado que la corrupción es mayor donde se producen procesos acelerados de redistribución negativa, tanto se trate de economías centrales o periféricas. Este no es un análisis economicista, sino ante todo políti$\mathrm{co}$, porque si se producen estas transformaciones es justamente porque (usando la terminología hegeliana) el Estado ha dejado su rol ético y se ha replegado a su fase meramente "negativa", de garante de derechos abstractos. Con todo, esta hipótesis tiene el problema de poder reducirse

\footnotetext{
1 Versiones preliminares de este trabajo se presentaron en el Seminario "A Sociedade contra o social" (São Paulo, diciembre de 2000, DF-FFLCH-USP) y en las "Segundas Jornadas de Ciencia Política. Crisis y perspectivas" (Buenos Aires, noviembre de 2002, FSOC-UBA).
} 
a una ecuación tan simplista como falsa: a mayor Estado, menor corrupción. Lo interesante de esta fórmula es que, al cabo, no es más que la inversión parcial de la presentada por el neoliberalismo (a menor estado, menos corrupción), cuya falta de adecuación con la realidad es también palmaria. ${ }^{2}$

¿Podremos afirmar entonces que la existencia de corrupción es independiente del tipo de Estado en cuestión? Creemos que no; que, en cambio, hay sí una relación íntima entre Estado y corrupción, aunque la misma no tenga nada que ver con el tamaño. Más concretamente, la hipótesis que trataremos de impulsar aquí es que la corrupción es inversamente proporcional a la cantidad de mediaciones implicadas en un régimen de representación democrático. Esto es, pensamos que la corrupción es mayor allí donde los representantes se encuentran más alejados de sus representados y por lo tanto, menos sometidos a su escrutinio. Esta relación, claro, no es geométrica, sino meramente tendencial.

Con todo, antes de comenzar, nos parece necesario hacer dos aclaraciones. Primero, a lo largo de estas páginas, usaremos el concepto "Corrupción" no sólo como sinónimo de cohecho o de la apropiación privada de bienes públicos sino también en un sentido más político y profundo de desatención (aunque no necesariamente traición) del mandato popular. Segundo, éste no es trabajo que pertenezca al campo específico de la "Ciencia Política", sino más bien al de la Teoría o la Filosofía Política; así pues, no se presentan aquí más que argumentaciones tentativas, sin datos que las corroboren ni indicaciones para su operacionalización. Eso, claro, no descarta la posibilidad de emprender esa tarea a futuro.

A continuación (1.) explicamos cuál es la plausibilidad de la hipótesis "dentro de un régimen democrático, a menores mediaciones corresponderá menos corrupción”. Luego (2.) pasamos revista al debate que se dio a fines del s. XVIII entre federalistas y antifederalistas, para extraer de allí algunos argumentos que nos ayuden a pensar en una democracia que sea a la vez moderna y des-mediada. Por último,

2 La Argentina es, en este sentido, un triste caso paradigmático. Duarante los años noventa, a medida que avanzaba el proceso de privatizaciones y el estado se "achicaba", los casos de corrupción documentados fueron aumentando en número y gravedad. 
(3.) explicamos por qué abrevar en argumentos como los de los antifederalistas no nos lleva necesariamente a pensar en una democracia carente de toda mediación y, por añadidura, lanzamos unas pocas propuestas concretas que pueden servir como líneas de trabajo a futuro.

\section{Corrupción y democracia, hipótesis tentativas}

El vocablo "corrupción", se aplica a aquellos elementos que se degradan siguiendo su curso natural (el metal que se oxida, la carne que se pudre, la madera que se corroe). En esta naturalidad, la corrupción aparece como inevitable; podemos intentar ralentizarla, pero nunca detendremos el proceso. Aunque mas no sea por las leyes de la termodinámica, nada escapa a aquella sentencia del Fausto de Goethe que Marx gustaba de citar: "Todo lo que existe merece perecer". En los textos clásicos, en la teoría neo-románica y hasta en algunos pensadores políticos modernos, este sentido es respetado y la corrupción y la degradación de la república se entienden como un fenómeno inevitable en el largo plazo. ${ }^{3}$

Empero, en lo que respecta a nuestro lenguaje cotidiano, cuando nos referimos al funcionario que coimea o el diputado que traiciona a sus votantes, pareciera que tenemos en vista actos que no son propios o consustanciales a la actividad política, sino más bien al contrario. Se ha operado un cambio, una inversión en el sentido de la palabra, según el cual, al hablar en términos éticos o ético políticos, la "corrupción" no aparece como natural, sino como antinatural. No obstante, esta es una idea demasiado apresurada y haremos bien en revisarla con un poco más de atención antes de aceptarla sin más.

Si pensamos en el acto de corrupción como contra natura, es porque estamos suponiendo una naturaleza honesta, recta (y a la postre incorruptible), del funcionario o representante político en tanto tal y

3 Así, por ejemplo, Rousseau dirá en Del Contrato Social “...cedo ou tarde acontece que o príncipe oprime, afinal, o soberano e rompe o tratado social. Reside aí o vício inerente e inevitável que, desde o nascimento do corpo político, tende sem cessar a destruí-lo, assim como a velhice e a morte destroem, por fim, o corpo do homem" (Rousseau, 1978, III. X). Por supuesto, hay excepciones a esta lectura, Harrington es un buen ejemplo de ello. 
olvidando que ese funcionario o ese representante tienen una vida privada, necesidades e intereses que surgen y se expresan por fuera de la esfera pública o estatal. Concretamente, lo que estamos pasando por alto es nada menos que la sociedad civil, el reino de la "eticidad perdida en sus extremos".

En efecto, en oposición a lo que sucede en otros ámbitos, en el seno de la sociedad civil (die bürgliche Gessellschaft), sí es corriente que los hombres vendan (e incluso se vendan) al mejor postor, independientemente de cómo se expresen en el momento del Estado. Al respecto, hay que recordar que no sólo Marx, sino también el mismo Hegel ${ }^{4}$ señalaron que las tensiones desatadas por la disgregación en el reino de la sociedad civil no se resolvían necesariamente dentro del Estado.

Aquí pareciera cobrar bríos la primera hipótesis que arrojamos (a mayor estado, menor corrupción), pero es una recuperación sólo aparente, porque, obviamente, los estados no son todos iguales. Un análisis simplista muestra, por ejemplo, que bajo un régimen despótico, un mayor aparato estatal implica más corrupción, pero que en un sistema democrático sucede lo contrario (Cf. Grondona, 1993; Klitgaard, 1994). ¿Estamos autorizados, entonces, a decir que a mayor democracia, menos corrupción? Si fuese así, este sería un fuerte argumento (prudencialista, es cierto) en apoyo de los regímenes democráticos. ${ }^{5}$ Sin embargo, y aunque algunos datos estadísticos parecen apoyar esta hipótesis (Klitgaard, 1994), hay otros argumentos a considerar antes de dar por cerrado el asunto.

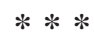

4 Marx lo hace a lo largo de casi toda su obra. De un modo más filosófico en la Crítica a la filosofía del derecho de Hegel, de forma más sociolpolítica en El 18 Brumario de Luis Bonaparte. Hegel por su parte, también acepta la persistencia del conflicto en el momento de la Eticidad, aunque de un modo más elíptico, en los últimos parágrafos referidos al Estado de su Introducción a la Filosofía del Derecho (Marx e Engels, 1955; Marx, 1980; Hegel, 1993; Lefebvre e Macherey, 1999).

5 Con todo, esta hipótesis simplista debería ser reformulada como "a mayor poder de un gobierno democrático, menos corrupción", con lo que no todo gobierno democrático sería un buen arma contra la corrupción, sino sólo aquellos en los que las instituciones fueran democráticas y poderosas (no importa, aquí al menos, como definamos esa fuerza). 
Cuando el grupo guerrillero argentino "Montoneros" secuestró, a mediados de los años setenta, a los hermanos Juan y Jorge Born obtuvo para su organización un rescate extorsivo de sesenta millones de dólares (el mayor de la historia del que se tenga noticia) y un buen puñado de cintas con las conversaciones mantenidas entre captores y cautivos. A diferencia de Juan, Jorge Born era un interlocutor locuaz y se interesó por conocer cuáles eran los objetivos políticos de sus raptores. Al tiempo que ellos le comentaban sus ideas para instaurar una "patria socialista" en la Argentina, el empresario -que era hijo de los dueños y directivo del holding multinacional "Bunge \& Born"- les explicaba detalles sobre los vericuetos del "poder real".

Una de las revelaciones que más impactaron a los Montoneros fue la descripción del "sistema de corrupción y connivencia" establecido entre las empresas y los gobiernos, no sólo de América Latina sino en todo el mundo. "Es normal, aquí y en cualquier parte, que las empresas importantes tengan a sueldo a los funcionarios de carrera y que coimeen a los políticos, los sindicalistas o los militares", aseguró el cautivo. En un pasaje de la charla, Jorge Born se lamentaba del dinero que perdían pagando a los burócratas sindicales (los gordos, como son llamados en la Argentina los representantes obreros más proclives al diálogo amigable con los empresarios), que cobraban mucho y pocas veces podían controlar a sus bases. "Al final, a veces tenemos que arreglar por derecha [esto es, por vías legales] con los delegados de fábrica... Cuando más cerca de la base, más exigen y más entregamos. Son más representativos y exigen cambios que tenemos que aceptar" (citado en Larraquy, 2000, p. 323 y ss.).

La enseñanza de Born podría resumirse así: a mayor cantidad de instancias de mediación, más oportunidades de corromper a un funcionario para que traicione los intereses que representa. Ahora bien, sucede que vivimos -nos guste o no- en una democracia representativa; nuestro sino, entonces, pareciera ser no poder evitar la corrupción. Es como si estuviésemos obligados a aceptar este fenómeno con la hidalga resignación de quienes saben que algo mejor es posible de pensar pero imposible de alcanzar.

Sin embargo, uno no puede evitar preguntarse si es realmente cierto que no existe una manera de escapar a las mediaciones que supone vivir bajo un régimen representativo sin destruirlo por completo. Es decir, cabe el interrogante acerca de si sería posible imaginar hoy 
una democracia moderna ${ }^{7}$ menos mediatizada que no sea quimérica ni tiránica, tal como lo hicieron los antifederalistas americanos hace doscientos años.

\section{Federalistas vs. antifederalistas, más allá de la constitución}

Es ya un lugar común afirmar que el autogobierno del pueblo no gozaba de buena prensa en siglo XVIII, pues ligando la democracia a la demagogia, los vicios del sistema eran subrayados y sus virtudes adjudicadas a los sistemas constitucionales en general. Empero, repasando los textos de los antifederalistas, se nota que no hay en ellos una denostación de la democracia como sí la hay en los Federalist Papers, donde se la supone un sistema perimido (Ketcham, 1986).

Efectivamente, en los textos antifederalistas, como en las Cato's o Agripa's Letters, podemos hallar varios y diversamente fundados elogios de la democracy (Ketcham, 1986; Duncan, 1994). Además, como notará Alexis de Tocqueville al asistir a su ocaso, los town-meetings, corazón institucional del antifederalismo, eran lo más parecido a una democracia de tipo griego, donde todos participaban sin distinciones de oficio, origen ni credo, siempre que fuesen miembros de alguna grey (Tocqueville, 1996, p. 83-5).

¿A qué se debe este énfasis antifederalista en la participación directa de los ciudadanos en el gobierno? A nivel práctico, por un lado, estaban los grandes propietarios y traficantes de esclavos (que eran tan antifederalistas como los radicales de izquierda) que no querían que el gobierno se entrometiera en sus negocios. Pero, por otra parte, el grueso de los partidarios antifederalistas eran pequeños granjeros y gente endeudada que veían que sus problemas sólo se solucionaban por la acción política, que sería entorpecida por el gobierno federal y su sistema de interminables mediaciones (Beard, 1998).

7 Si bien hay casos de corrupción documentados en la polis ateniense, tal como lo destaca Sabine (1990), el quid de la cuestión es que una democracia "antigua" como la de Atenas, es por definición menos mediada y, en este sentido, si nuestra hipótesis fuera cierta, menos proclive a la corrupción. De todos modos, nótese que los pensadores modernos que retoman la idea de un régimen inmediato (Rousseau es el mejor ejemplo) no tenían en mente a Atenas sino a Esparta. 
Ya desde una óptica más profunda, menos ligada a los intereses inmediatos, puede verse en los Antifederalist Papers un "idealismo" (aunque quizás este término no sea el más adecuado) enraizado en el republicanismo clásico, según el cual la vida social se asienta sobre la comunidad y la virtud. La tesis es que un pueblo virtuoso se expresa, necesariamente, a través de asociaciones virtuosas $\mathrm{y}$, al cabo, de un gobierno virtuoso (con todo, cf. infra, donde relativizamos esta visión).

En contrapartida, los federalistas fundan el gobierno al modo de los iusnaturalistas, a partir de individuos que -aunque obligados por leyes naurales, v.g., no convencionales- se comportan de un modo más o menos egoísta. Afirma John Jay que la Confederación, el régimen al que de un modo $\mathrm{u}$ otro se aferraban los antifederalistas, lejos de facilitar la seguridad de sus miembros, la pone en peligro constante. James Madison, en una frase con reminiscencias kantianas, afirma que si los hombres fueran ángeles no requerirían de gobierno alguno, mas que no siendo el caso, precisan de uno. Alexander Hamilton traza una analogía entre los estados confederados y los individuos en Estado de Naturaleza: "Las naciones vecinas son naturales enemigas a no ser que su debilidad común las obligue a unirse en una República Confederada, y su constitución evite las diferencias que ocasiona la proximidad..." (Hamilton et al., 1994).

En ausencia de una instancia superior, de un umpire que decida en casos de controversias, cualquier ofensa puede desencadenar una guerra civil sin final. Retomando los argumentos del Second Treatise (Cf. Locke, 2001, II.§§ 123-31), ${ }^{8}$ Hamilton advierte que "cuando se desenvaina la espada, las pasiones de los hombres olvidan toda moderación" si no hay quien les ponga coto. Para preservar la seguridad y la felicidad de las ex colonias, no cualquier gobierno puede ser efectivo, es necesario uno fuerte y centralizado, por encima "de las pasiones del pueblo" (Hamilton et al., 1994, nro. 16).

$$
* * *
$$

8 Creemos que hay varias buenas razones por las cuales sostener que el emparentamientode los Federalistas con la teoría lockeana es más válido que con la hobbeseana. En este sentido, el principal argumento es que los autores de los Federalist Papers dan otras razones, además de la seguridad, por las que la adhesión a la nueva Constitución sería conveniente. Entre estas razones, el progreso económico conjunto y la protección de las libertades ocupan un lugar preponderante. 
En su trabajo sobre los orígenes del pensamiento político moderno, Quentin Skinner señala que en el devenir de la teoría política de los últimos siglos puede observarse dos abordajes muy diferentes. El primero de ellos afirma que si la ingeniería con la que se construye el gobierno es efectiva, es decir, si las instituciones son fuertes, no importará si se cuenta o no con hombres virtuosos, pues la corrupción se presentará sólo allí donde la maquinaria falle. El segundo abordaje sugiere que si los hombres que controlan las instituciones son corruptos, de nada valdrá el andamiaje institucional que se monte y que -por el contrario- cuando se cuenta con hombres virtuosos, la cuestión institucional pasa a un segundo plano (Skinner, 1978, v. I, p. 44-5). Esta distinción podría todavía ser refinada para distinguir dentro del segundo grupo a los pensadores elitistas -aquellos que creen que sólo el grupo destinado a dirigir debe ser virtuoso- de los pensadores "plebeyistas" 9 -que suponen que es el pueblo en general el que debe permanecer virtuoso.

Sería posible, en principio, poner ejemplos concretos de integrantes de estos tres grupos, refiriéndonos al debate constitucional americano de 1787. En el primer conjunto podríamos colocar, sin mayores problemas a James Madison y en el último a George Washington. El problema es que, contrariamente a lo que podría pensarse, no es tan sencillo colocar a los antifederalistas en el segundo grupo. Y esto es así no sólo por la diversidad de argumentos que reina entre ellos, sino porque, como lo muestra Manin (1994), los antifederalistas no confiaban tan sólo en la virtud generalizada del pueblo americano, cuanto en una combinación de ésta con sabias instituciones republicanas que pusieran coto a los apetitos de poder. Sólo así es posible entender la discusión que llevaron adelante tanto en la convención de Filadelfia cuanto a través de los periódicos políticos.

$$
* * *
$$

Uno de los puntos en donde más claras quedan las diferencias entre federalistas y antifederalistas es en el tratamiento que ambos hacen del problema de las facciones. Tanto los republicanos clásicos cuanto los modernos radicales antifederalistas apuntaban que el mismo podía resolverse sólo eliminando sus fuentes. Había que fundar repúblicas sólo donde la gente ya fuese libre e igual entre sí; sentar las bases de un gobierno libre sólo donde la virtud pudiese ser la guía de todos. Los

9 Me sirvo aquí de los argumentos y la terminología de Cícero Araujo (2002). 
antifederalistas suponían que en América estaban dadas las condiciones para semejante organización por haber una mayoría de pequeños propietarios (Kenyon, 1962; Ketcham, 1986; Duncan, 1994). Los federalistas estaban en desacuerdo con la idea y ofrecían otra solución a la cuestión.

Madison define las facciones como un grupo "esté en mayoría o minoría" que se mueve por un interés adverso a los derechos de los demás ciudadanos, o a los intereses permanentes de la comunidad considerados en conjunto. Mas, ¿̇cuáles son estos "intereses de la comunidad" que deben ser protegidos incluso contra la mayoría? Madison no contesta de forma taxativa a este interrogante, pero sí insinúa una respuesta al explicar que el origen de las facciones y "la fuente de discordia más común y persistente es la desigualdad en la distribución de propiedades" (Hamilton et al., 1994, nro. 10; Beard, 1998, p. 156-7). ${ }^{10}$

Lejos de una postura rousseauniana, ${ }^{11}$ lo que proponen los federalistas no es "resolver" la cuestión (ya sea mediante la redistribución de propiedades o a través de un impuesto progresivo), ${ }^{12}$ sino "ordenarla" $y$-hasta cierto punto- obtener beneficios de ello. Dado que es imposible o indeseable eliminar las causas de las facciones, lo que se debe es suprimir sus efectos nocivos a través de: 1) la multiplicación de intereses (que al oponerse se anulan entre sí o incluso originan mejoras, al estilo

10 En contra de esta interpretación económica originada en el trabajo seminal de Beard (1998) sobre los orígenes de la constitución americana, David Epstein (véase su estudio de El Federalista número diez, en Epstein, 1987, p. 87-155) ha subrayado la importancia de la distinción entre las facciones por intereses (económicamente fundadas) y las facciones por pasiones (ideológicas o religiosas). De acuerdo con la visión de Epstein, son las segundas las que se revelan como más peligrosas a un gobierno libre. En general, estamos de acuerdo con la postura de Epstein. Sin embargo, a pesar de argumentar fuertemente esta interpretación más política, Epstein en ningún momento coloca en duda la importancia de la visión económica señalada por Beard. Esto es, aunque el problema de las facciones no pueda limitarse a lo económico, tampoco puede circunscribirse a lo político. Véase también la visión de Gaido (2001).

11 En Del Contrato Social, Rousseau insiste en la necesidad de una distribución de propiedades tal que no haya nadie tan pobre como para verse obligado a venders ni tan rico como para tener la posibilidad de comprar a otro (Rousseau, 1978).

12 De hecho, los federalistas se muestran escépticos con respecto a la conveniencia de los impuestos directos (Cf., por ejemplo, Hamilton et al., 1994, nro. 12). 
mandevilliano) y 2) del moderno gobierno republicano, diferente de la democracia pura (Hamilton et al., 1994, nro. 10).

Mientras que en la democracia pura manda una mayoría que puede ser tirana, en la república moderna gobiernan representantes que no son mera caja de resonancia de la sociedad, sino que tamizan y depuran la opinión pública para que coincida con el interés público. En este sentido, dice Madison, los representantes conocen lo que el pueblo requiere mejor que él mismo (Hamilton et al., 1994, nro. 10).

Los constitucionalistas contemporáneos suelen señalar como gran virtud del sistema madisoniano a los frenos y contrapesos que ejercen censura sobre leyes "apresuradas". Los antifederalistas ven justamente allí el mayor de los vicios: la cristalización del poder de los que ya lo detentan (Manin, 1994; Gargarella, 2000). Los checks \& balances protegen a las minorías, de acuerdo, pero el problema es que una minoría puede estar imponiendo su interés a la mayoría. Y si es cierto, como parecen afirmar los federalistas, que las desavenencias entre las personas se originan a causa de la propiedad, los que están siendo frenados en sus ímpetus son, ante todo, los pequeños propietarios y los desposeídos.

Los antifederalistas sostenían que era la sociedad por entero (y no apenas un grupo de elite) la que tenía que ser virtuosa. Con todo, para asegurarse que esa virtud se mantendría a lo largo del tiempo, era necesario servirse de las enseñanzas del Barón de Montesquieu y mantener una organización tal que permitiese esa preservación. De acuerdo con ellos, esto incluía una separación clara, simple y completa de los poderes de gobierno y no los frenos y contrapesos en los que pensaban los federalistas. Además, los antifederalistas hacían hincapié en la necesidad de declarar de forma positiva los derechos de los que no podrían ser privados los ciudadanos (lo que a la postre se convertiría en la Bill of Rights) y en la importancia de mantener -hasta donde fuese posible- las instituciones de participación política lo más activas y directas posible.

La lógica que guiaba a los antifederalistas no les hacía proponer ni la democracia directa (pero sí su aceptación de ser esta posible, como en los gobiernos locales) ni un simple gobierno de la mayoría (después de todo, ellos también temían a las mayorías federales que podían destruir las autonomías locales y sus instituciones de autogobierno). Ciertamente, una separación completa de las ramas de gobierno como la 
pretendida por los antifederalistas en lugar de los frenos y contrapesos propuestos por sus adversarios hubiese llevado a una "supremacía limitada" de la rama más popular (la Cámara de Representantes). Sin embargo, eso es muy distinto a afirmar, como lo ha hecho cierta historiografía revisionista, que los antifederalistas propulsaban un gobierno de corte populista o incluso de tiranía de la mayoría. ${ }^{13}$

$$
* * *
$$

Así pues, las críticas más profundas de los antifederalistas contra el sistema federal se basaban en la convicción de que éste último pretendía apagar la voz del pueblo en tanto que cuerpo que se mueve y que exige. Hamilton admite este hecho con claridad en El Federalista número sesenta y tres, cuando afirma que la característica principal de la nueva constitución no es tanto la representación (que, de una u otra manera estuvo siempre presente en las repúblicas antiguas de Grecia, Roma y el norte de Italia), sino ofrecer un gobierno en el que la representación excluye la participación directa del pueblo en su conjunto:

“(...) el principio de la representación no era desconocido de los antiguos ni totalmnte ajeno a sus constituciones políticas. La verdadera diferencia entre estos gobiernos [se refiere, concretamente a Esparta, Creta, Roma y Atenas] y el americano [tal como es propuesto en El Federalista] reside en la exclusión total del pueblo, en su carácter colectivo, de toda participación en éste, no en la exclusión total de los representantes del pueblo de la administración de aquéllos..." (Hamilton et al., 1994, nro. 63)

En el fondo, la cuestión en discusión es que mientras que para los federalistas la representación era un gran avance, para los antifederalistas era un paliativo necesario; mientras que los primeros pretendían que los representantes no se limitaran a transmitir la opinión de sus electores sino que la "refinaran", los segundos pugnaban por un sistema lo más cercano a la democracia directa que fuese viable, aceptando inclusive la participación in-mediata, cuando fuese posible (Cf. Gargarella, 2000).

El razonamiento de los antifederalistas era el siguiente: dado que el interés público es el interés de la mayoría del pueblo y que el

13 En Manin (1994), puede encontrarse una argumentación detallada sobre este punto. 
mismo se ventila en la Cámara de Representantes, ¿̇por qué permitirle a otros departamentos que cercenen esa superioridad? ¿Por qué admitir el veto presidencial sobre las leyes, un resabio del poder absoluto de los monarcas? ¿Por qué admitir que el senado, la cámara menos popular, tenga competencias judiciales y ejecutivas? ¿Por qué permitir que el departamento menos democrático, el judicial, sea el último revisor de las leyes? Pero, por sobre todo, ¿̇por qué razón un puñado de hombres conocería mejor lo que le conviene al pueblo que el pueblo mismo?

En este sentido, en los escritos del Federal Farmer se exige, a la manera de Rousseau, que los representantes puedan dictárles instrucciones a los representantes y que los mismos puedan ser revocados si no cumplieran con su mandato. Así, si la democracia directa se revela imposible, ya sea por razones técnicas o por la falta de virtud política de los ciudadanos, en lugar de archivarla hay que intentar recuperarla mediante instituciones que nos acerquen ella. Brevemente: no hay que hacer de la Necesidad virtud, sino convertir a la Virtud en una necesidad (Ketcham, 1986; Gargarella, 2000).

Los federalistas pusieron todas sus energías en la superposición relativa de los tres poderes y en la exclusión absoluta de la participación directa y ganaron el debate constitucional. Los antifederalistas, que apostaron a reforzar la virtud que veían en una sociedad de "iguales" a través de una serie de instituciones republicanas, perdieron. ${ }^{14}$ Sin embargo, el debate no está, aún hoy en día, cerrado por completo. Es claro que no se puede simplemente retroceder de forma acrítica para abrevar en una discusión que está en muchos puntos ultrapasada y que parece sólo interesar a historiadores de las ideas. No obstante, nos parece que en los textos antifederalistas hay muchas ideas y argumentos para aprovechar, pues su potencial no es poco, sobre todo pensando en sociedades donde la apatía y la falta de participación activa se han convertido caldo de cultivo de dirigencias cada vez más alejadas de sus mandantes.

14 Por supuesto, no estamos proponiendo negar las profundas diferencias sociales existentes en los Estados Unidos del s. XVIII, originadas no sólo en la división de clases, sino también en la de sexos, razas y religiones. En todo caso, aquí nos interesa seguir, siquiera en abstracto, el potencial de las ideas antifederalistas, independientemente de la poca o mucha adecuación de sus diagnósticos a la realidad de su tiempo. 


\section{Individuo, libertad y propiedad}

Sería un gran error trasladar sin más el debate entre federalistas y antifederalistas a la discusión contemporánea entre liberales y comunitaristas. Si bien los antifederalistas se basaban en parte en un republicanismo tradicional que tiene varios puntos en común con el moderno comunitarismo, ${ }^{15}$ lo cierto es que su raciocinio no tenía como punto de partida a la comunidad sino a los individuos, pero se trataba de individuos que no eran -para usar una expresión cara a Marx- "mónadas aisladas" o "seres abstractos", sino personas concretas, insertas en un contexto determinado. Pero, ¿̇es acaso posible pensar en o incluso desde el individuo sin caer en un individualismo egoísta que transforme en huera la reflexión sobre la virtud y la república? En principio, pensamos que sí, puesto que los conceptos de Individuo y el de Individualismo no están conectados de un modo necesario. Al respecto, hay un pasaje de John Dunn que nos gustaría traer a colación para aclarar la diferencia:

"Tener individualidad es tener algo distintivo y ser un individuo no es otra cosa que el común destino humano. Pero ser individualista es abrazar ese destino con sospechosa alacridad: hacer de la necesidad un vicio. Tener individualidad -al menos como aspiración- no es sino hacer lo que nos es propio... Pero ser individualista es algo que tiende a no tener en cuenta los intereses de los demás o negar la presencia de todo compromiso afectivo fundamental para con los otros. Tener individualidad es una categoría casi puramente estética y a la postre una categoría afirmativa. Ser individualista es claramente una categoría moral con una fuerte deriva hacia lo negativo" (Dunn, 1996, p. 55)

Así pues, no es que los antifederalistas estuvieran pensando en una libertad antigua y oponiéndola a una moderna, ${ }^{16}$ sino que, a la

15 Sobre similitudes y diferencias entre comunitarismo y republicanismo, pueden consultarse las obras de Pettit (1999) y Gargarella (1999).

16 Nos referimos, claro, a la clásica distinción de Constant, retomada y reformulada por Berlin (1969), según la cual hay una libertad antigua (positiva, republicana) y una moderna (negativa, liberal). En el tratamiento de Berlin, las diferencias no son tanto históricas como normativas, llevándose la peor parte la libertad positiva. En principio, estamos en desacuerdo con la diferenciación de Berlin (pueden consultarse al menos tres argumentaciones distintas en contra de la posición de 
manera de Hegel o de Marx, trataban de establecer un diálogo entre las dos. Ese diálogo sería posible en una democracia que no obedeciera ni al modelo antiguo (que destruía o al menos restringía la libertad negativa) ni al moderno propuesto por los federalistas (que imposibilitaba rebasar esa libertad negativa, privada). Pero, ¿qué democracia sería esa?

Cuando los antifederalistas sugerían que en la América del Norte dieciochesca estaban dadas las condiciones para instituir una república libre, basaban su visión en el supuesto de que todos (o casi todos) sus potenciales ciudadanos ${ }^{17}$ eran pequeños propietarios $y$, así, hombres libres, autónomos en el sentido de no depender de nadie para su sustento. La condición de propietario para el ejercicio de la libertad es tan antigua como la teoría política: aquél que no es dueño de su cuerpo (esclavo) no puede ser libre; quien no puede extender su propiedad más allá de sus manos (siervo) no puede ser libre; quien no puede plasmar su propiedad en una obra acabada y venderla (proletario) no puede ser libre. Y dado que un pueblo libre está formado de hombres libres, éste sólo puede ser conformado por hombres que tengan una igual propiedad $y$, por ende, una igual libertad.

Aquí nos encontramos con una versión ridículamente reduccionista de la libertad (al punto que, de desmontar el argumento igualitarista, lo que nos resta es la definición neoliberal de Nozick). Sin embargo tendremos que aceptar ese reduccionismo, siquiera como un momento de la libertad, pues como bien advirtió Hegel, las libertades negativas precisan de él y de su institucionalización. Además, a su vez, esas libertades negativas son el presupuesto de la libertad comunal o colectiva en un moderno mundo democrático. En palabras de la teoría crítica:

"La libertad comunal es una libertad que por medio de las instituciones y prácticas de una sociedad, por medio de la autocomprensión, el interés y las costumbres de los ciudadanos, se ha convertido en un objetivo común. La libertad negativa muda su carácter cuando se convierte en preocupación común.

Berlin en el libro de Miller, 1991). Sin embargo, hemos creído que para los fines de este trabajo es útil mantenerla.

17 Ver supra, n. 14. 
Pues entonces no sólo queremos cada uno nuestra propia libertad, sino que también perseguimos un máximo de autodeterminación para todos. Tal espacio común de autodeterminación sólo puede haberlo si hay un espacio institucionalizado de libertad pública en el que nosotros, en el medio de la discusión pública y de la praxis democrática, ejercitemos nuestros derechos de autodeterminación como derechos políticos. Mientras la libertad negativa, mediante instituciones y prácticas de autodeterminación colectiva se transforme en libertad comunal, tal libertad comunal, donde exista, habrá de ser necesariamente autoreflexiva: se convierte en su propio objetivo" (Wellmer, 1996, p. 73)

Nuestra tesis es que la mudanza en libertad comunal de las libertades negativas requiere que tomemos en serio la propuesta política de los antifederalistas. Debemos obligarnos a volver a pensar en el modo de instrumentar una democracia lo menos mediada posible. Pero, cuidado, hay que desmediar nuestra democracia, sin por eso hacerla inmediata (algo que, además de difícilmente practicable, resulta oneroso y poco eficaz, como lo muestra Janine Ribeiro, 2000). Esa, nos parece, es además la medida anticorrupción más efectiva que pueda imaginarse de resultar cierta la hipótesis que extrajimos de la enseñanza de Jorge Born: cuantas menos mediaciones se establecen, menos oportunidades encuentra el corruptor para lograr su cometido.

$$
* * *
$$

Se han repetido hasta el hartazgo distintos argumentos según los cuales reinsertar la libertad positiva en el mundo moderno sería tanto improbable cuanto indeseable. Es cierto que una visión pedagógica o mística del asunto nos puede llevar a pensar eso, sobre todo al tomar los ejemplos de las trágicas experiencias del siglo XX. Sin embargo, tenemos la impresión de que pueden trazarse (y caminarse) otras sendas. Una democracia des-mediada no nos hará más morales, pero sí nos permitirá ser más políticos y justamente de eso se trata toda esa historia. Creemos que a medida que se eliminan los tamices que "depuran" la voz popular, las instituciones políticas democráticas que están dentro de la sociedad civil cobran relevancia y así se van tornando dispositivos de transformación que crean libertad positiva (a partir) de las libertades negativas e interés común (a partir) de los intereses individuales. Claro que para que esto sea así tenemos que suponer, junto con la teoría crítica, que al lado de la racionalidad estratégica (o 
más bien, en diálogo con ella) convive una racionalidad intersubjetiva (comunicativa) en la que el otro no es el límite de mi libertad sino su condición de posibilidad.

Las experiencias en las que se intenta recuperar el perdido espíritu del town-meeting, tal como la del presupuesto participativo que se emprendió en Rio Grande do Sul, aún no han sido lo suficientemente estudiadas. Sin embargo, parece claro que los primeros resultados han sido satisfactorios en el doble sentido de evitar casos de corrupción y promover mecanismos tendientes a la transformación a la que hicimos referencia.

La des-mediación de la democracia moderna es un proceso, no un objetivo, pues de lograr una democracia inmediata (en el supuesto caso que esto fuese posible) estaríamos cercenando las libertades negativas que nos habíamos propuesto preservar para mantenernos dentro de la modernidad. En cuanto proceso, la des-mediación se nos aparece como un trabajo cotidiano en el sentido de una interacción y una politización que se producen de modo constante sin llegar nunca a ningún final.

Es probable que los especialistas en corrupción acierten al decir que la corrupción como fenómeno es imposible de erradicar por completo. Puede que eliminar de forma definitiva la figura del político que no hace lo que prometió (y que hace aquello sobre lo que no habló) sea una tarea titánica. Sin embargo, nos parece que una paulatina y sensible merma de casos como estos es plausible con un cambio que poco tiene de utópico. Nos referimos no sólo a orientar nuestra mirada a la tan mentada "teoría de la democracia deliberativa" sino a avanzar con propuestas concretas de que apunten a una reforma político institucional. Elementos clave de esa reforma serían, sólo por poner algunos ejemplos, los subsidios universales; ${ }^{18}$ la participación (siquiera en

18 No me refiero a ninguna de las posturas particulares al respecto, aunque tengo en mente la visión de Van Parijs (1995) que en Brasil fue retomada por un proyecto del Senador Eduardo Suplicy y que en la Argentina es impulsada por el Frente Nacional contra la Pobreza (FreNaPo). Obviamente, el razonamiento que está por detrás de esta idea es el de satisfacer (siquiera en una medida pequeña, a modo de parche posible aquí y ahora) aquél requisito planteado por los antifederalistas: el de contar con un pueblo conformado por individuos que puedan exteriorizar su libertad, vivir autónomamente. 
pequeña proporción) de la ciudadanía en la elaboración de presupuestos y la adjudicación de partidas; ${ }^{19}$ una transformación del poder judicial mediante su socialización (con la introducción de juicios por jurados) y su politización (quitándole a los jueces la última palabra con respecto a cuestiones valorativas); ${ }^{20}$ la restricción del poder de la Cámara de Senadores, limitando su competencia a cuestiones federales o regionales y el control de los diputados y funcionarios políticos (con la introducción de la revocatoria de mandatos por parte de los electores). ${ }^{21}$

Ciertamente, llegamos al final de estas páginas con más deudas de las que hubiese sido deseable: partimos de una hipótesis sobre la corrupción que no testeamos ni corroboramos (aunque es posible hacerlo) y presentamos una tesis teórica huérfana de apoyo (pero creemos que trabajando en una ligazón entre la noción de racionalidad de la teoría crítica y algunos proyectos democráticos de los antifederalistas sería plausible fortalecerla). Pensamos que ahondar sobre el tema puede ser viable y, por añadidura, fructífero en más de un sentido. Sin embargo, nuestro espacio se agota y este trabajo termina precisamente aquí.

\section{Referências bibliográficas}

Araúso, Cícero. Estado y Democracia. In: Boron, A. (Ed.). Teoría y filosofía política. La recuperación de los clásicos en el debate latinoamericano. Buenos Aires: CLACSO, 2002, p. 269-90.

BEARD, Charles A. An economic interpretation of the Constitution of the United States. New Brunswick: Transaction Publishers, 1998.

BERLIN, Isaiah. Two concepts of liberty. In: Four essays on liberty. Oxford University Press, 1969.

Duncan, Christopher. Men of a different faith: the anti-federalist ideal in early american political thought. Polity, v. 3, n. 26, 1994.

DunN, John. La agonía del pensamiento político occidental. London: Cambridge University Press, 1996.

19 Esta es una obvia referencia a la iniciativa que ha dado en llamarse Orçamento participativo a la que ya mencionamos en más arriba.

20 Aquí me sirvo de observaciones Gargarella (1995).

21 Estas últimas dos propuestas, de lejos las más controvertibles, no pueden ser desarrolladas aquí. Sin embargo, quisiera subrayar que en ambos casos se trata de proyectos realizables y no de meras elucubraciones. 
EpsteIn, David F. La Teoría Política de "El Federalista". Grupo Editor Latinoamericano, 1987. (Estudios Políticos y Sociales).

GabetTA, Carlos. República o país mafioso. Al cabo de cuatro gobiernos en democracia. Le monde diplomatique. Edición Cono Sur, 2002.

GAIDO, Daniel. The popular interpretation of american history: a materialist revision. Science \& Society, v. 65, n. 3, p. 350-75, 2001.

GARGARELla, Roberto. El ideal de la democracia deliberativa en el análisis del sistema representativo. Sociedad, v. 6, p. 76-109, 1995.

. Las teorías de la justicia después de Rawls. Un breve manual de filosofía política. Barcelona: Paidós, 1999.

. En nombre de la Constitución: el legado de los federalistas dos siglos después. In: Boron, A. (Ed.). La filosofía política moderna. De Hobbes a Marx. Buenos Aires: CLACSO-Eudeba, 2000.

GrondonA, Mariano. La corrupción. Buenos Aires: Planeta, 1993.

HaLimi, Serge. Enron, símbolo de un sistema. Un escándalo casi legal. Le monde diplomatique. Edición Cono Sur, 2002.

Hamilton, Alexander et al. El Federalista. México D. F.: Fondo de Cultura Económica, 1994.

Hegel, G. W. F. Fundamentos de la filosofía del derecho. Madrid: Libertarias/ Prodhufi, 1993.

Janine Ribeiro, Renato. A sociedade contra o social: o alto custo da vida política no Brasil. São Paulo: Cia. das Letras, 2000.

KENYON, J. Republicanism and radicalism in the American Revolution: An oldfashioned interpretation. William and Mary Quarterly Third Series, v. 19, n. 2, 1962.

KetChAm, Ralph. The Anti-Federalist Papers and the Constitutional Convention Debates. New York: Mentor, 1986.

KLITGAARD, Robert. Controlando la corrupción. Una indagación práctica para el gran problema social de fin de siglo. Buenos Aires: Sudamericana, 1994.

Larraquy, M.; Caballero, M. Galimberti. De Perón a Susana, de Montoneros a la CIA. Buenos Aires: Grupo Editorial Norma, 2000.

LefeBvre, Jean-Pierre; Macherey, Pierre. Hegel e a sociedade. São Paulo: Discurso Editorial, 1999.

LOCKE, John. Dois tratados sobre o governo. São Paulo: Martins Fontes, 2001.

MANIN, Bernard. Checks, balances and boundaries: the separation of powers in the constitutional debate of 1787. In: FonTANA, B. (Ed.). The invention of the modern republic. New York: Cambridge University Press, 1994, p. 27-62.

MarX, Karl. Escritos de juventud. México D. F.: Fondo de Cultura Económica, v. 1, 1980. (Obras Selectas). 
MarX, Karl; Engels, Friedrich. Obras Escogidas. Moscú: Editorial Progreso, v. $1,1955$.

MilLER, David. (Ed.). Liberty. Oxford readings in politics and government. New York: Oxford University Press, 1991.

Pariss, Philippe Van. Real freedom for all: what (if anything) can justify capitalism? New York: Oxford University Press, 1995.

PetTIt, Philip. Republicanismo. Una teoría sobre la libertad y el gobierno. Barcelona: Paidós, 1999.

Rousseau, Jean-Jacques. Do Contrato Social. São Paulo: Abril Cultural, 1978. (Os Pensadores).

SABINE, George H. Historia de la teoría política. México D. F.: Fondo de Cultura Económica, 1990.

SkINNER, Quentin. The foundations of modern political thought. New York: Cambridge University Press, 1978.

Tocqueville, Alexis de. La democracia en América. México D. F.: Fondo de Cultura Económica, 1996.

WelLmer, Albrecht. Finales de partida: la modernidad irreconciliable. Madrid: Ediciones Cátedra-Universidad de Valencia, 1996. 